\title{
Obesity and Metabolic Dysregulation in Childhood: A Review
}

\section{Priyanka Bhateja ${ }^{1}$ and Roosy Aulakh ${ }^{2 *}$}

${ }^{1}$ Senior Resident, Department of Pediatrics, Government Medical College and Hospital, Chandigarh, India

${ }^{2}$ Professor, Department of Pediatrics, Government Medical College and Hospital, Chandigarh, India

*Corresponding Author: Roosy Aulakh, Professor, Department of Pediatrics, Government Medical College and Hospital, Chandigarh, India.
Received: April 05, 2020

Published: May 07, 2020

(C) All rights are reserved by Priyanka

Bhateja and Roosy Aulakh.

\begin{abstract}
Obesity these days had become a major health problem with prevalence both in developed as well as in developing countries. Overweight and obese children are likely to stay obese into adulthood [1]. While overweight and obesity are themselves risk factors to develop non communicable diseases like diabetes and cardiovascular diseases (CVD) at younger age, their association with metabolic dysregulation further increases the risk. The objective of this article is to identify the causes of obesity, to highlight its association with metabolic dysregulation and to suggest ways to prevent it, so as decrease co-morbidities associated with it Keywords: Overweight; Obesity; Metabolic Dysregulation; BMI
\end{abstract}

What is overweight and obesity?

Overweight is defined as $\mathrm{BMI}>85^{\text {th }}$ percentile and obesity as BMI $>95^{\text {th }}$ percentile [2]. However as per age specific cut offs for overweight and obesity, overweight is defined as BMI $>23 \mathrm{~kg} / \mathrm{m}^{2}$ of adult equivalent and obesity is defined as $>28 \mathrm{~kg} / \mathrm{m}^{2}$ of adult equivalent [3].

\section{What are the causes of obesity?}

The main causes of obesity are

- Changing lifestyle which promotes more of indoor activities and decrease outdoor activities.

- $\quad$ More intake of junk food and carbonated drinks.

- Lack of physical exercise.

- Genetic factors.

- Excessive screen time, hence decreasing time for physical activity (National health and nutritional examination survey (NHANES) has shown a strong correlation between physical activity and overweight. Physical activity has been shown to prevent and to treat obesity [4].

What is metabolic syndrome?

Metabolic syndrome (MS) refers to constellation of findings related to reduced insulin sensitivity and increased risk of CVD. It includes obesity, insulin resistance, glucose intolerance, hypertension, dyslipidemia, hyperandrogenism and polycystic ovary syndrome in women.
Why is there growing concern about metabolic syndrome?

There is growing evidence on the prevalence of components of MS among obese children and adolescents. Obesity and metabolic syndrome are associated with endothelial dysfunction, atherogenic dyslipidemia and increases the risk of development of cardiovascular diseases and type 2 diabetes mellitus (T2DM) [5,6]. Obesity has a negative effect on immunity due to alterations in lymphoid tissue architecture and increase fat deposition in bone marrow and thymus hence causing changes in distribution of leukocyte subsets and lymphocyte activity [7-9]. Metabolic syndrome further promotes increase of proinflammatory mediators in adipose tissue which block the production of insulin sensitizing adipokines like adiponectin [10]. Further metabolic syndrome is characterized by low plasma HDL levels which has anti-inflammatory and immunoregulatory properties [11]. HDL neutralizes LPS, located on outer membrane of gram negative bacteria, thus protecting against endotoxin induced inflammation and shock [12]. Low HDL levels in obese persons may fail to effectively sequester LPS, further causing metabolic disease progression and immune cell activation [13-15].

Obesity and metabolic syndrome are independent risk factors for chronic kidney disease (CKD) and end stage renal disease (ESRD) [16-18]. Obesity related kidney disease, now termed as obesity related glomerulopathy (ORG) has histological finding of increased glomerular size and glomerular sclerosis $[19,20]$. These occur before decreased kidney function and often presents as isolated proteinuria with or without renal insufficiency. 
How obesity is linked to metabolic syndrome?

Metabolic syndrome is caused by insulin resistance which is induced by circulating free fatty acids (FFA) from adipose tissue mass. FFA reduce insulin sensitivity by inhibiting insulin-mediated glucose uptake hence causing hyperinsulinemia. Besides obesity causes increased secretion of adipokines which affect food intake and cause changes in vascular system which results in endothelial dysfunction and atherosclerosis [21].

Risk factors for metabolic syndrome have origin in prenatal and early post-natal period. Maternal gestational diabetes, low birth weight, infant feeding practices and early adiposity rebound are associated with development of obesity and metabolic syndrome later in life. Both genetic and environmental factors have been linked to obesity as well as metabolic syndrome. Environmental factors include short duration of sleep, unhealthy eating habits, excessive screen time and tobacco smoke exposure. Genome wide linkage analyses have shown common genetic factors responsible for individual components of the metabolic syndrome. Besides blood pressure, lipid profile and obesity are themselves highly heritable and show significant family aggregation.

What are the comorbidities associated with obesity and metabolic syndrome?

Comorbidities associated with obesity, insulin resistance and metabolic syndrome include obstructive sleep apnea, polycystic ovary syndrome, nonalcoholic fatty liver disease (NAFLD), type 2 DM. Besides this obese people are at greater risk for depression and social stigma related to being overweight also contributes to mental illness.

Does obesity lead to depression in children?

Obesity and stress have been linked through many ways. Stress, causing increase in peripheral cortisol and catecholamine levels result in increased insulin secretion and decrease in growth hormone and sex steroid secretion causing accumulation of fat in visceral adipose tissue [22-24].

Stress and depression causing disturbance in the circadian rhythm of cortisol secretion may contribute to development of central obesity and metabolic syndrome $[25,26]$. Studies have shown high prevalence of anxiety and depression in overweight and obese children $[27,28]$.

What screening to be done for obesity and metabolic syndrome?

Obesity prevention in childhood and adolescence should be first line approach to decrease the risk of metabolic syndrome and CVD. Primary care clinicians should perform annual obesity screening for all children by using BMI and children with BMI at or greater than 95th percentile should be referred for weight management program and dietary counseling should also be provide to such children

In addition to obesity screening, children should be screened annually for elevated blood pressure. Lipid profile should be done for all children between 9 - 11 years of age and those with family history of dyslipidemia. Screening for glucose intolerance and type $2 \mathrm{DM}$, should also be done using fasting glucose levels, oral glucose tolerance test, $\mathrm{HbA} 1 \mathrm{C}$ levels and random glucose levels.

What are the treatment options for obesity and metabolic syndrome?

Treatment options mainly include dietary modifications, lifestyle modifications as well as pharmaco-therapeutic interventions.

CHILD-1 (Cardiovascular health integrated lifestyle diet-1), a diet consisting of evidence based recommendation for dietary changes to reduce cardiovascular risk in pediatric population [29].

CHILD-1 involves 5 different age groups from birth to 21 years of age. Following table is based on the recommendations for each group with certain modifications proposed.

Lifestyle interventions include increase in physical exercise decrease in screen time, decrease intake of artificially-sweetened beverages. Children should be encouraged to be active for weight control and for physical well-being. The WHO recommends atleast 30 minutes of cumulative moderate exercise for all ages; and for children an additional 20 minutes of vigorous exercise three times a week [30].

Pharmacotherapeutic options to treat obesity are limited in children. FDA has approved only orlistat for weight loss in adolescents $>12$ years of age. Orlistat is an intestinal lipase inhibitor causes 3\% weight loss at 6 months of age based on initial weight. Bariatric surgery although effective, is reserved for severely affected adolescents.

\section{Summary}

Metabolic dysregulation and metabolic syndrome reflects the effect of insulin resistant on human physiology.

- $\quad$ Risk factor are mostly multiple and cluster together, aim should be to prevent obesity and promote a healthy lifestyle.

- Focus for clinical screening and treatment should be on cardiometabolic risk factors.

- Screening should be done for obesity, glucose abnormalities, hypertension, dyslipidemia. 


\begin{tabular}{|c|c|}
\hline Age & ons \\
\hline $\begin{array}{c}\text { Birth } \\
\text { to } 6 \\
\text { months }\end{array}$ & $\begin{array}{l}\text { - } \\
\text { - } \\
\text { - } \\
\text { No top feeds } \\
\text { birth } \\
\text { - Infants should be exclusively breast fed until } 6 \\
\text { months of age }\end{array}$ \\
\hline & $\begin{array}{l}\text { - } \quad \text { Continue breast feeding until } 24 \text { months of age. } \\
\text { - } \quad \text { tart home based easily available complemen- } \\
\text { - No restriction in fat intake without medical rec- } \\
\text { ommendation. } \\
\text { - Water should be encouraged. } \\
\text { - Limit other types of drinks to } 100 \% \text { fruit juice, } \\
\text { intake of which should be limited to } 4 \text { ounces/ } \\
\text { day or less. } \\
\text { - Avoid sweetened beverages. }\end{array}$ \\
\hline & $\begin{array}{l}\text { - } \quad \text { Switch to reduced fat milk ( } 2 \% \text { to fat free). } \\
\text { - } \quad \text { Limit or avoid sugar sweetened drinks. } \\
\text { - } \quad \text { Water should be encouraged. } \\
\text { - } \quad \text { Transition to table food with total fat content } \\
\text { of } 30 \% \text { of daily kcal/estimated energy require- } \\
\text { ment (EER), saturated fat content of } 8-10 \% \text { of } \\
\text { daily kcal/EER and monounsaturated and poly- } \\
\text { unsaturated fat content of up to } 20 \% \text { of daily } \\
\text { kcal/EER. } \\
\text { - } \\
\text { - } \\
\text { Tvoid trans fat as much as possible. }\end{array}$ \\
\hline & $\begin{array}{ll}\text { - } & \text { Fat free milk. } \\
\text { - } & \text { Limit or avoid sugar sweetened drinks. } \\
\text { - } & \text { Water should be encouraged. } \\
\text { - } & \text { Limit total fat to } 25-30 \% \text { of daily kcal/EER, satu- } \\
\text { rated fat content of } 8-10 \% \text { of daily kcal/EER and } \\
\text { monounsaturated and polyunsaturated fat con- } \\
\text { tent of up to } 20 \% \text { of daily kcal/EER. } \\
\text { - } \\
\text { - } \\
\text { - } \\
\text { - } & \text { Enotal trans fat as much as possible. } \\
\end{array}$ \\
\hline & $\begin{array}{l}\text { - } \quad \text { Fat free milk. } \\
\text { - } \quad \text { Limit or avoid sugar sweetened drinks. } \\
\text { - } \quad \text { Water should be encouraged. } \\
\text { - } \quad \text { Limit total fat to } 25-30 \% \text { of daily kcal/EER, satu- } \\
\text { rated fat content of } 8-10 \% \text { of daily kcal/EER and } \\
\text { monounsaturated and polyunsaturated fat con- } \\
\text { tent of up to } 20 \% \text { of daily kcal/EER. } \\
\text { - } \quad \text { Avoid trans fat as much as possible. } \\
\text { - } \quad \text { Total daily cholesterol less than } 300 \mathrm{mg} \\
\text { - } \quad \text { Encourage high dietary fiber intake from foods. }\end{array}$ \\
\hline
\end{tabular}

Table
- Children with the presence of multiple components of metabolic syndrome are at maximum risk and need most intensive intervention efforts to achieve risk reduction.

- Increasing awareness of comorbid conditions such as NAFLD, PCOS, obstructive sleep apnea, mental health disorders enables pediatricians to refer to specialists as needed.

\section{Bibliography}

1. Singh AS., et al. "Tracking of childhood overweight into adulthood: a systematic review of the literature". Obesity Reviews 9.5 (2008): 474-488.

2. Barlow SE and Expert C. "Expert committee recommendations regarding the prevalence, assessment, and treatment of child and adolescent overweight and obesity: summary report". Pediatrics 120.4 (2007): S164-S192.

3. Khadilkar V., et al. "Body Mass Index Cut-offs for screening for Childhood Overweight and Obesity in Indian Children". Indian Pediatrics 49 (2012): 29-34.

4. Church TS., et al. "Trends over 5 decades in U.S. occupationrelated physical activity and their associations with obesity". PLoS One 6.5 (2011): e19657.

5. Huang PL. "A comprehensive definition of metabolic syndrome". Disease Models and Mechanisms 2 (2009): 231-237.

6. Expert Panel on Detection, Evaluation, and Treatment of High Blood Cholesterol in Adults. Executive summary of the third report of the National Cholesterol Education Program (NCEP) Expert Panel on Detection Evaluation, and Treatment of High Blood Cholesterol in Adults (Adult Treatment Panel III)". The Journal of the American Medical Association 285 (2001): 24862497.

7. Kanneganti TD and Dixit VD. "Immunological complications of obesity". Nature Immunology 13 (2012): 707-712.

8. Yang Youm YH., et al. "Obesity accelerates thymic aging”. Blood 114 (2009): 3803-3812.

9. Karlsson EA., et al. "Diet-induced obesity in mice reduces the maintenance of influenza-specific CD8+ memory T cells". Journal of Nutrition 140 (2010): 169-167.

10. Guilherme A., et al. "Adipocyte dysfunctions linking obesity to insulin resistance and type 2 diabetes". Nature Reviews Molecular Cell Biology 9 (2008): 367-377.

11. Andersen CJ and Fernandez ML. "Dietary approaches to improving atheroprotective HDL functions". Food and Function 4 (2013): 1304-1313. 
12. Levine DM., et al. "In vivo protection against endotoxin by plasma high density lipoprotein". Proceedings of the National Academy of Sciences of the United States of America 90 (1993): 12040-12044.

13. Mogensen TH. "Pathogen recognition and inflammatory signaling in innate immune defenses". Clinical Microbiology Reviews 22 (2009): 240-273.

14. Cani PD., et al. "Metabolic endotoxemia initiates obesity and insulin resistance". Diabetes 56 (2007): 1761-1772.

15. Hansel B., et al. "Metabolic syndrome is associated with elevated oxidative stress and dysfunctional dense high-density lipoprotein particles displaying impaired antioxidative activity". The Journal of Clinical Endocrinology and Metabolism 89 (2004): 4963-4971.

16. Fox CS., et al. "Predictors of new-onset kidney disease in a community based population". The Journal of the American Medical Association 291.7 (2004): 844-850.

17. Hsu CY., et al. "Body mass index and risk of end stage renal disease". Annals of Internal Medicine 144.1 (2006): 21-28.

18. Kramer H., et al. "Obesity and prevalent and incident CKD: the hypertension detection and follow-up program". American Journal of Kidney Diseases 46.4 (2005): 587-594.

19. Kambham N., et al. "Obesity-related glomerulopathy: an emerging epidemic". Kidney International 59.4 (2001): 14981509.

20. Praga M., et al. "Clinical features and long term outcome of obesity-associated focal segment glomerulosclerosis". Nephrology Dialysis Transplantation 16.9 (2001): 1790-1798.

21. Huang PL. "A comprehensive definition for metabolic syndrome". Disease Models and Mechanisms 2 (2009): 231-237.

22. Charmandari E., et al. "Pediatric stress: hormonal mediators and human development". Hormone Research in Paediatrics 59.4 (2003): 161-179.

23. Pervanidou P and Chrousos GP. "Stress and obesity/metabolic syndromein childhood and adolescence". The International Journal of Pediatric Obesity 6.1 (2011): 21-28.

24. Charmandari E., et al. "Endocrinology of the stress response". Annual Review of Physiology 67 (2005): 259-284.

25. Nader N., et al. "Interactions of the circadian CLOCK system and the HPA axis". Trends in Endocrinology and Metabolism 21.5 (2010): 277-286.
26. Charmandari E., et al. "Peripheral CLOCK regulates target-tissue glucocorticoid receptor transcriptional activity in a circadian fashion in man". Plos One 6.9 (2011): e25612.

27. Onyike CU., et al. "Is obesity associated with major depression?. Results from the Third National Health and Nutrition Examination Survey". American Journal of Epidemiology 158.12 (2003): 1139-1147.

28. Pervanidou P., et al. "Cortisol profiles, and depressive symptomatology, and body mass index ina clinical population of obese children". Stress 16.1 (2013): 34-43.

29. Expert panel in integrated guidelines for cardiovascular health and risk reduction in children and adolescents: summary report". Pediatrics 128.5 (2011): S213-S256.

30. World Health Organization. "Health Education and Health Promotion Unit. Annual global move for health initiative a concept paper". World Health Organization (2003).

\section{Assets from publication with us}

- Prompt Acknowledgement after receiving the article

- Thorough Double blinded peer review

- Rapid Publication

- Issue of Publication Certificate

- High visibility of your Published work

Website: $w$ ww.actascientific.com/

Submit Article: www.actascientific.com/submission.php Email us: editor@actascientific.com

Contact us: +919182824667 